\title{
23. PETROGRAPHY AND MINERALOGY OF SAPROPELS
}

\author{
Wladimir D. Nesteroff, University of Paris VI, France
}

\section{INTRODUCTION}

Superficial sapropels were known from piston core investigations throughout the eastern Mediterranean Basin (Olausson, 1960 and 1961; Ryan, 1970). Leg 13 drilling showed that sapropels are associated with marl oozes of hemieuxinic facies in sapropelitic series which occurred during a limited number of periods (Figure 1). We identified two such periods in the Quaternary and one in the upper Pliocene.

In addition, we found that sapropels could be associated with turbidity and contour current processes and redeposited within the sequences of turbidites and contourites.

The first sapropels, which were first described by Kullenberg (1952) and Olausson (1960, 1961), are black sediments, rich in organic matter and devoid of benthonic foraminifera. Reputedly, they are deposited under euxinic bottom conditions corresponding to stagnant phases of the basins.

\section{STRATIGRAPHY}

Two types of sapropelitic series were encountered in our drilling. The pelagic sapropelitic series, similar to those described in the piston cores (Olausson, 1960, 1961), are interbedded with pelagic nanno oozes on the topographic highs. The current-redeposited sapropels are admixed into turbidite and contourite sequences and occur in the sedimentary fill of trenches and topographic lows.

\section{Pelagic Sapropel Series}

The pattern of sapropels within pelagic sedimentation is constant and a type sequence can be presented. They are always interbedded (with sharp contacts) with the nanno oozes characteristic of the hemipelagic and pelagic deposits of the eastern Mediterranean Basin. These pelagic oozes are well bedded, highly calcareous, light-colored, "bready" in texture, and often exhibit scattered foraminifera on the surface of the freshly split cores.

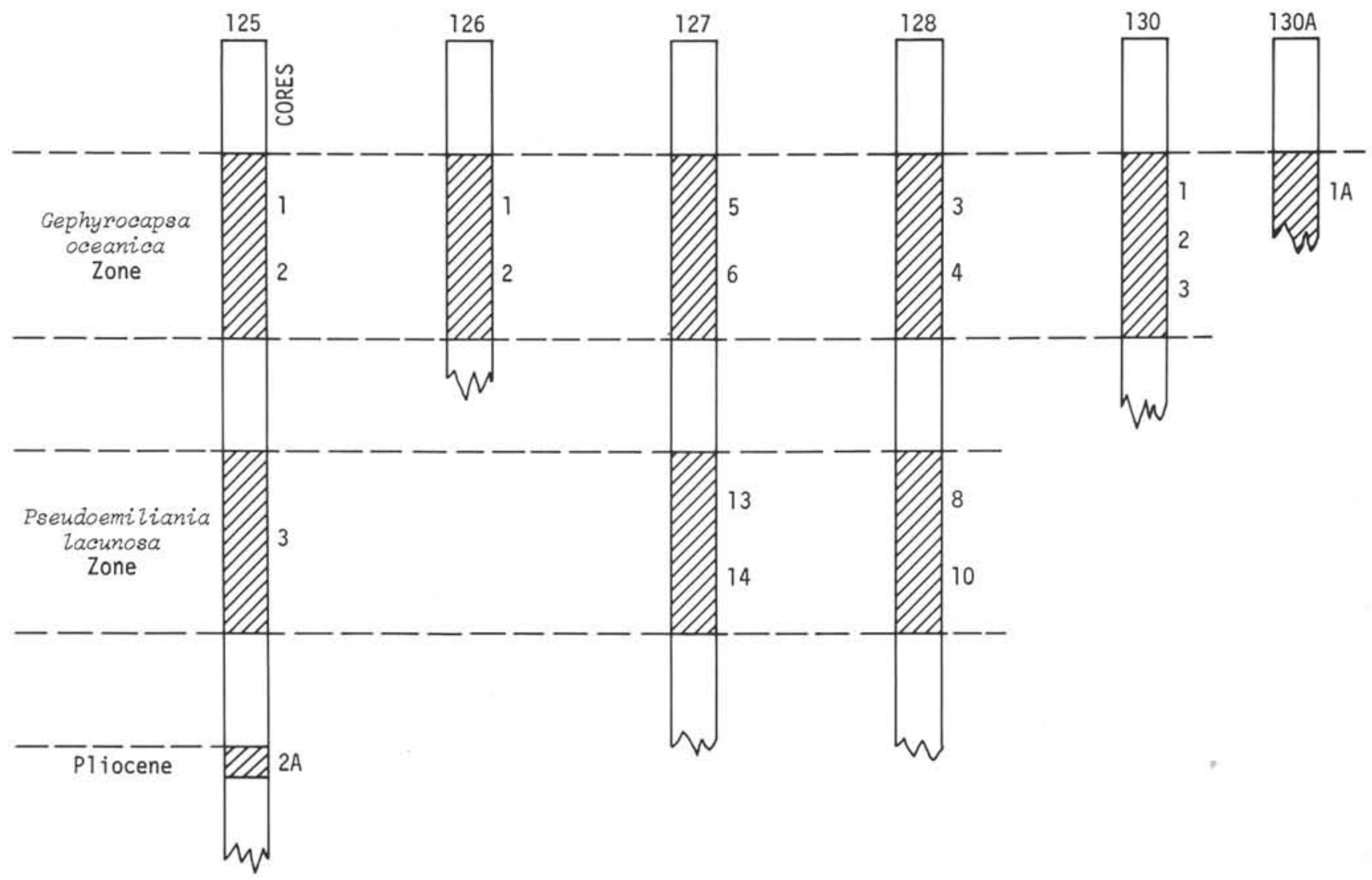

Figure 1. The distribution and age of sapropels in the eastern Mediterranean Basin, based upon Leg 13. 
The sapropelitic sequences are darker in color, displaying all hues from gray to dark brown and black. They consist of a succession of gray marl oozes and black sapropel beds, occasionally interrupted by a layer of normal pelagic ooze. The details of the succession within the series may be complicated, but always start with a layer of gray marl ooze which is overlain by a layer of black sapropel. The sapropel is topped by a new layer of gray marl ooze or, occasionally, by a bed of pelagic nanno ooze. (see Figure 2).

The beds of gray marl ooze are plastic (and not "bready"), 1 to $10 \mathrm{~cm}$ thick, devoid of visible foraminifera, and contain a lower percentage of carbonate.

The sapropel beds are black, 1 to $3 \mathrm{~cm}$ thick, and "bready" in texture. Calcium carbonate content is medium to low. The sapropels overlie the gray marl oozes with sharp contacts. Occasionally, this contact is gradational, and in this core, a layer of gray marl ooze grading into sapropel is observed (125-3-4). This suggests a progressive installation of sapropelitic conditions. Millimetric laminae of sapropels are interbedded in the gray marl oozes, testifying to very short sapropelitic episodes. The upper limit of the sapropel beds is also extremely sharp, indicating a sudden end to the stagnant conditions.

During Leg 13 drilling, we recovered pelagic sapropels from the Ionian Sea, on the Mediterranean Ridge (Site 125). They were interbedded in the 80-meter-thick blanket of Quaternary and Pliocene pelagic nanno and marl oozes (Site 125, Core 1, 3 and 2A; see Table 1). We also encountered sapropels in the eastern part of the Mediterranean Ridge, north of the Nile Delta (Site 130), where they were interbedded within the thin nanno ooze blanket (Figure 3) of Recent age overlying the Nile turbidites.

\section{The Sapropelitic Turbidite Sequences}

Sapropel-stained turbidites and contourites were recovered at three sites in the eastern Mediterranean Basin. To our knowledge, these beds have not been previously reported in the literature. These unique beds were observed in the turbidite infill. Quaternary in age, they were found in the cleft in the Mediterranean Ridge (Site 126) and in the Hellenic Trough (Sites 127 and 128). The current-deposited character of these beds is testified by cross-and oblique bedding, sand-silt laminae, the intercalation of winnowed beds of foraminifera, etc. The sapropelitic material is, in each individual bed, nonuniformly mixed with the detrital or hemipelagic material. In some cases, only the coarse or the fine parts of the sequences are admixed, while in other cases, sequences are completely stained black. Thus, the sapropel layers display all shades of dark hues from light brown to black $(\mathrm{N} / \mathrm{O})$. They are always interbedded with sharp contacts with the light-colored non-sapropelitic series (Figures 4 and 5).

At Site 126, the Quaternary infill of the cleft in the Mediterranean Ridge contains rare sapropel layers interbedded with normal turbidites and contourites. The sapropel sequences are turbidites of the sand-clay type. They begin with a thick, 5-to $35-\mathrm{cm}$, often clayey, layer of foraminiferal sand, which grades upward into a plastic marl ooze of olive gray color. The sequences, 10 to $45 \mathrm{~cm}$ thick, are always separated by sharp limits (126, Cores 1 and 2$)$. An exception is a thin layer of nongraded sapropel and gray marl oozes at Site 126 which may well be part of a short pelagic series interbedded in the bulk turbidites (126-2-3, 82 to $77 \mathrm{~cm}$ ).

In the Hellenic Trough (Sites 127 and 128) the sedimentary column of turbidites and contourites, Quaternary in age, presents two series of sapropel-stained sequences. We informally refer to the first as the Upper Sapropel $(0.65 \mathrm{my})$ and to the second as the Lower Sapropel (1.5 my) (see Chapter 9). The Upper Sapropel is characterized by sequences with a high sand-silt to clay ratio. Two examples are given in Figure 4. The sequences. start with a thick layer of sand comprised mainly of quartz and rock debris. The sands are overlain, with sharp contacts, by a black (5Y 2/2) marl ooze. Thin layers of sands, silts, and sand balls occur above (Figure 5, 127-6, Sections 2 and 3).

The Lower Sapropel consists of much fine-grained sediments organized in thin sequences of contourites. Of note are abundant diatoms and a general yellowish olive color. The sequences, 3 to $5 \mathrm{~cm}$ thick, are divided into halves. The lower is comprised of sapropel, a stiff, "bready"-textured sediment of yellowish color. It grades upward into a light gray plastic marl ooze. In addition, thin, millimetric, black laminae occur in the marl oozes and occasionally in the sapropels. These may correspond to a concentration of fine, dark debris by the contour currents (Figure 5, 127-14-5).

\section{MINERALOGY}

Mineralogy of the pelagic sapropelitic series is different from that of the hemipelagic nanno oozes with which they are interbedded. The gray marl oozes are different in a discrete way, and the sapropel beds are fundamentally different.

The calcium carbonate content of the gray marl oozes is lower (30 to $40 \%$ ) than it is in the pelagic nanno oozes (60 to $80 \%$ ). In addition, in some samples, high-magnesium calcite represents approximately one-half of the carbonate (125-1-3, $70 \mathrm{~cm}$ and 1-4-120) while this mineral is absent in the pelagic oozes. The quartz content is slightly higher, 8 versus 5 per cent, and the clay mineral content is consistently higher (50 versus $80 \%$ ) than in the pelagic nanno oozes. However, the clay mineral assemblage remains similar to that of the pelagic series. At Site 125, we noted well-crystallized illite together with open illite and smaller amounts of montmorillonite, kaolinite, and chlorite. Also of note was a greater proportion of amorphous material.

Thus the gray marl oozes are pericontinental deposits in which terrigenous clastics, clays, and quartz dominate over biogenic components. However, an important difference exists between the common pericontinental deposits and the gray marl oozes of the sapropelitic series. In the latter, small amounts of gypsum (1 to $2 \%$ ) are present.

If the gray marl oozes are, to a certain extent, comparable to normal pelagic sedimentation, the sapropel layers are quite different. Their most important characteristic is a very high organic and amorphous matter content, reaching 60 , and even 80 per cent in some beds. This may be observed on SEM pictures which show the poor crystallinity of sapropels (Figure 6). Analyses of organic matter were carried out on two of the sapropel beds. They 

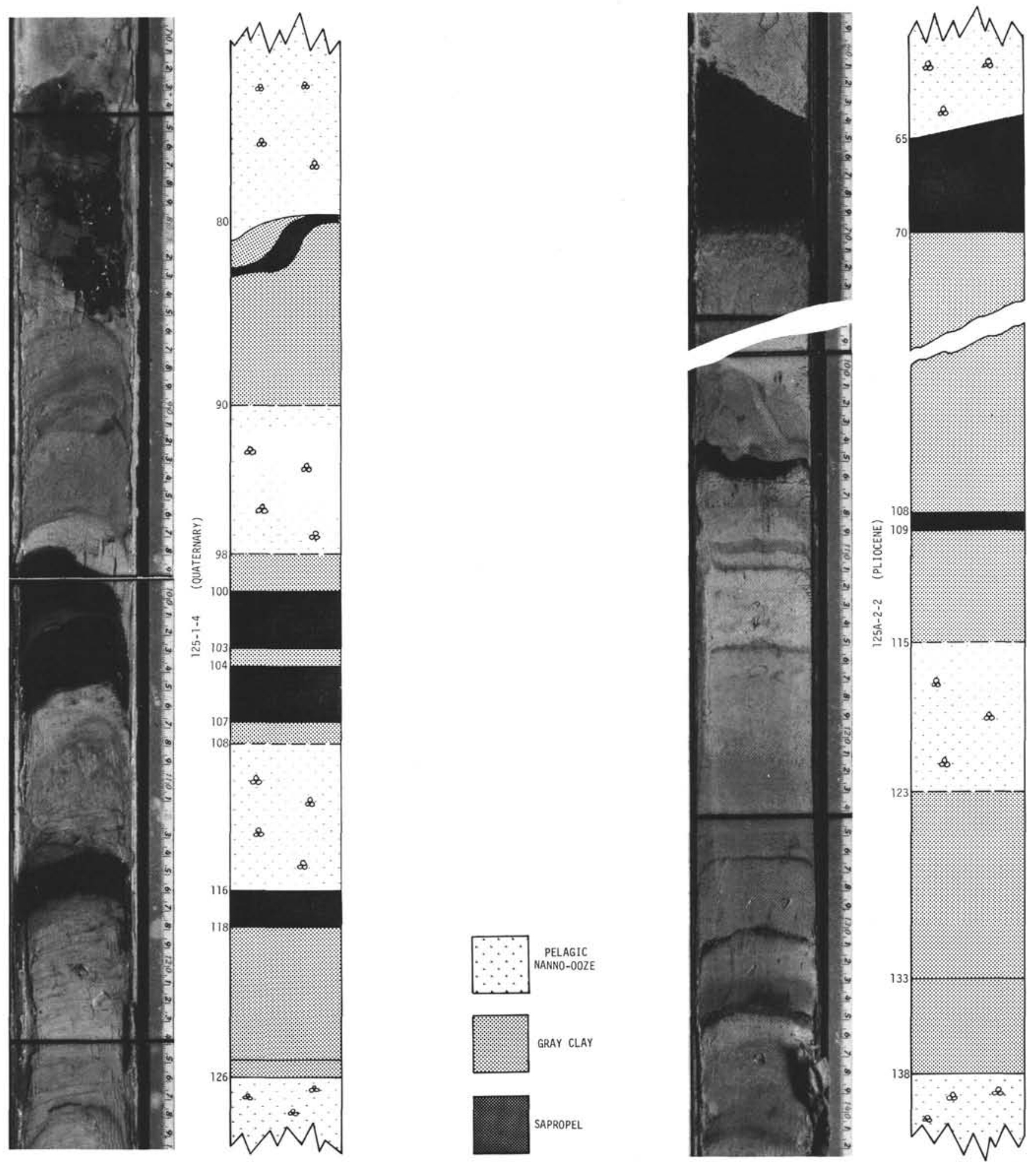

Figure 2. Pelagic sapropels from the Mediterranean Ridge. The sapropelitic series are sharply interbedded with the hemipelagic deposits of Site 125. In each series, a layer of plastic gray marl ooze underlies and, generally, overlies the black sapropel bed. However, a pelagic nanno ooze may directly top some sapropels. In addition, two or more sapropel beds may occur in a section of gray marl ooze (125-1-4 and 125A-2-2). 


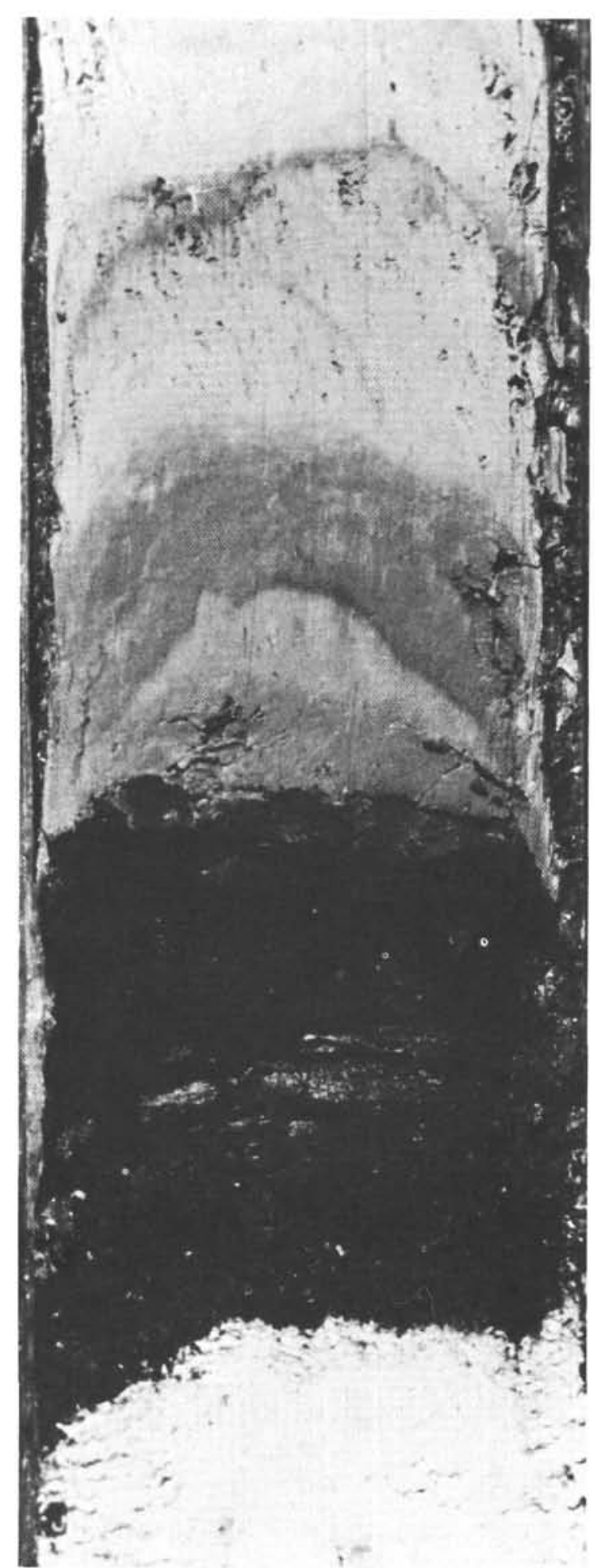

Figure 3. Sapropel layer interbedded in pelagic nanno ooze beds of Site 130, on the Mediterranean Ridge. The sapropel, $5 \mathrm{~cm}$ thick, is black $(\mathrm{N} / \mathrm{O})$ and displays a "bready" texture. It is neither preceded nor followed by the usual gray marl ooze. (130-2-3, 79 to $60 \mathrm{~cm})$.

show that the kerogen content is exceptionally high (4 to $5 \%$ ), and that the degree of degradation, about 50 , corresponds to a $\mathrm{C} / \mathrm{H}$ ratio of about 10 . This points to the
TABLE 1

Detailed Disposition of Sapropel Beds and Sapropelitic Turbidite and Contourite Sequences in the Recovered Cores

\begin{tabular}{|c|c|c|c|}
\hline Site & Core & Section & $\begin{array}{l}\text { Interval } \\
(\mathrm{cm})\end{array}$ \\
\hline \multirow[t]{9}{*}{125} & 1 & 3 & $\begin{array}{l}46-48 \\
66-67 \\
75-75.5\end{array}$ \\
\hline & & 4 & $80^{*}$ \\
\hline & & & $100-103$ \\
\hline & & & $103.5-107$ \\
\hline & & & $116-118$ \\
\hline & & & $115^{* *}$ \\
\hline & 3 & 1 & $133-140$ \\
\hline & & 4 & $37-59$ \\
\hline & & 5 & $\begin{array}{l}40-54 \\
58-73 *\end{array}$ \\
\hline \multirow[t]{3}{*}{$125 \mathrm{~A}$} & 2 & 2 & $63-70$ \\
\hline & & & $108-108.5$ \\
\hline & & & $133^{* *}$ \\
\hline \multirow[t]{7}{*}{126} & 1 & 1 & $98-116$ \\
\hline & & & $122-150$ \\
\hline & & 2 & $0-9$ \\
\hline & & & $12-17$ \\
\hline & & 3 & $60-90$ \\
\hline & 2 & 3 & $78-80$ \\
\hline & & 5 & $59-134$ \\
\hline \multirow{9}{*}{127} & 5 & 6 & $\begin{array}{l}138-143 \\
143-150\end{array}$ \\
\hline & 6 & 2 & $\begin{array}{r}143-150 \\
0-140\end{array}$ \\
\hline & & 3 & $0-100$ \\
\hline & & 6 & $140-150 * *$ \\
\hline & 13 & 1 & $120-136$ \\
\hline & 14 & 3 & 4-33 \\
\hline & & 4 & $42-44$ \\
\hline & & 5 & $0-150$ \\
\hline & & 6 & $10-13$ \\
\hline \multirow[t]{11}{*}{128} & 3 & 4 & $124-150$ \\
\hline & & 5 & $\begin{array}{c}0-6 \\
131-140\end{array}$ \\
\hline & & 6 & $\begin{array}{c}131-140 \\
10-20\end{array}$ \\
\hline & & & $92-66$ \\
\hline & & & $100-125$ \\
\hline & 4 & 4 & $130-139$ \\
\hline & 10 & 2 & $128-137$ \\
\hline & & 3 & $0-150$ \\
\hline & & 4 & $0-20$ \\
\hline & & & $133-150$ \\
\hline & 11 & 3 & $140-150$ \\
\hline \multirow[t]{5}{*}{130} & 1 & 1 & 115 \\
\hline & & 2 & $100-110$ \\
\hline & 2 & 3 & $\begin{array}{l}25-27 \\
71-76\end{array}$ \\
\hline & 3 & 2 & $\begin{array}{l}71-76 \\
58-62\end{array}$ \\
\hline & & & $110-130$ \\
\hline $130 \mathrm{~A}$ & 1 & 1 & $148-150$ \\
\hline & & & \\
\hline
\end{tabular}

primitive character of this organic matter (Table 2). In addition, a 15 -minute pyrolysis at $300^{\circ} \mathrm{C}$ yielded a fair amount of complex degradation products (Bordenave, et al., 1967; Giraud, 1970). The chromatographic analysis showed that they correspond to a domain between $\mathrm{C}_{1}$ and $\mathrm{C}_{12}\left(250-550^{\circ} \mathrm{C}\right)$. They contain alcohol and acids, thus confirming again the non-evoluted character and the marine origin of the organic matter.

The calcium carbonate content of sapropels is variable. In some beds it is similar to that of the gray marl ooze: 30 


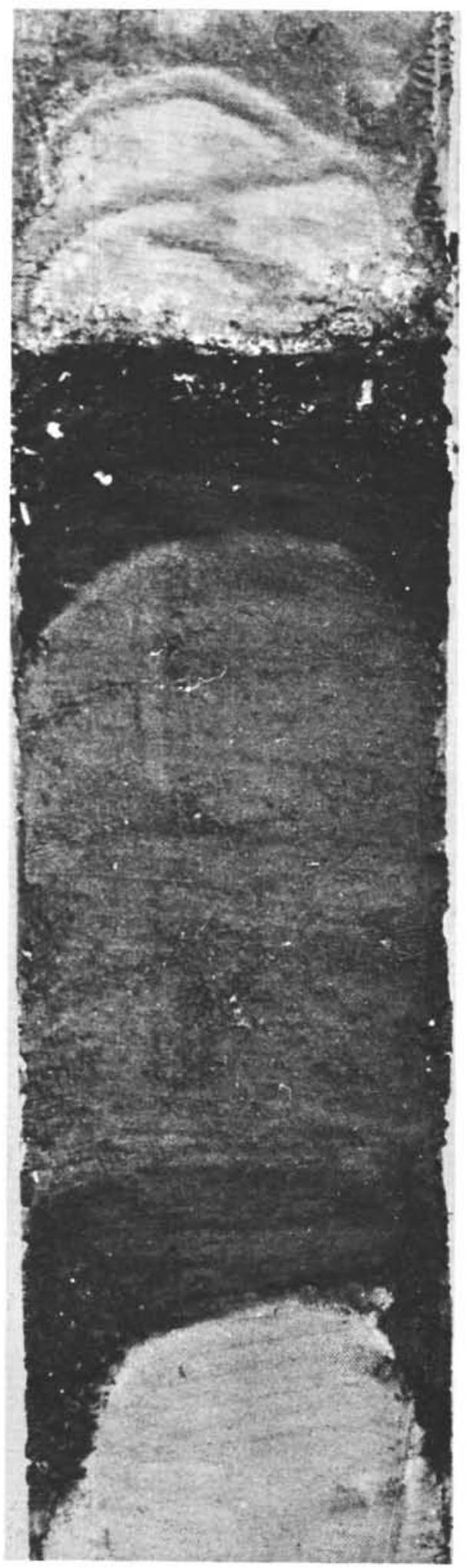

Figure 4. Characteristic sequences of the Upper Sapropel of the Hellenic Trough $(128-3-5,35$ to $13 \mathrm{~cm})$. The first sequence starts with a black foraminiferal-quartzose clayey sand which grades upward into a marl ooze of lighter color. The second sequence is reduced to the basal layer of dark sand. It is overlain by a new sapropelitic sequence which starts by a cross-bedded white foraminiferal sand. to 40 per cent. In other layers, it is low and, in rare cases, the calcium carbonate is even absent $(125-3-1,136 \mathrm{~cm})$.

The quartz content is also lower $(2 \%)$ in the sapropels than in the gray marl oozes, which suggests that the terrigenous input is diluted by abundant organic and amorphous matter.

The most characteristic difference between sapropels and gray marl oozes is found in the clay mineral assemblages. In the sapropel beds of Site 125, they consist of open illite, chlorite, kaolinite, and montmorillonite. The well-crystallized illite noted in the gray marl oozes and the pelagic nanno oozes is absent.

Gypsum content is also higher. It increases from 2 per cent in the gray marl oozes to 6 to 8 per cent in the sapropel beds. The gypsum crystals should be minute, because they are not observed under the microscope but are noted only on the X-ray diffractograms.

Iron content is especially high. Electron microscope scanning shows that the iron is disseminated as tiny crystals throughout the sample (Figure 6). This is a typical distribution of authigenic minerals in deep-sea sediments. Generally, no large crystals are observed during the first stages of neogenesis. We have observed this mechanism for iron oxides, manganese, and silica.

The mineralogical analysis of sapropelitic turbidites and contourites has shown only small differences with the sapropel-free sequences. The sapropelitic beds are richer in organic matter and contain small amounts of gypsum. No difference was noted in the clay mineral assemblages. This could have been expected, as all the materials originally deposited in different environments as nanno oozes, gray marl oozes, and sapropels are mixed during transport by currents and are redeposited together.

\section{Age of the Sapropelitic Deposits}

Sapropels reflect severely restricted conditions, and throughout the same basin they should occur during the same periods.

In the Mediterranean Sea, sapropels were known only in the eastern basin, and our drillings confirmed this distribution. All recovered sapropels belong to three well-defined periods (Figure 1). This was expected for the sapropels interbedded with hemipelagic oozes deposited particle-byparticle. In addition, we found that turbidity and contour current-redeposited sapropels also belong to these periods. This indicates that, in the regions we investigated, the residence time of the sediments in the area feeding the turbidity currents is very short

Two of the sapropel periods occur in the Quaternary and the third in the upper Pliocene. The first period, informally named Upper Sapropel (see Chapter 9) coincides with the Gephyrocapsa oceanica Zone. It corresponds to the Bruhnes/Matuyama interval and is dated at $0.65 \mathrm{my}$. The second period, informally named Lower Sapropel, coincides with the Pseudoemiliania lacunosa Zone. It corresponds to the Matuyama/pre-Jaramillo interval and is assigned an age of about 1.5 my.

The third sapropel period belongs to the upper Pliocene. It was observed only on the Mediterranean Ridge at Site 125 (Core 2A, Section 2). It corresponds to the Matuyama/Gauss interval and was assigned an age of $2.4 \mathrm{my}$ (see Chapters 19 and 46). 

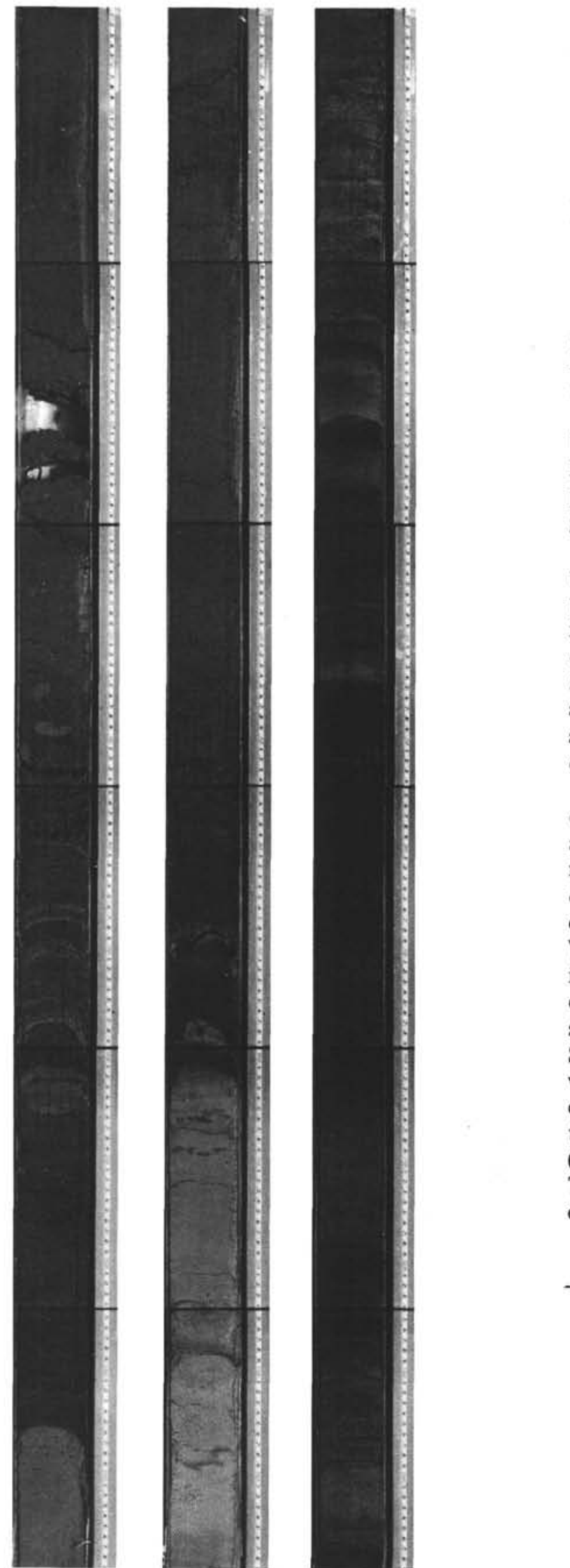

7900 BP. (Olausson, 1961 and 1965; Wijsmstra, 1965; Ryan, 1970; Rossignol and Pastouret, 1971; Chamley, 1971). This was because of poor recovery of superficial sediments.

From a climatic point of view, it is interesting to note that the sapropels occur during the warm trends, as attested by the faunal assemblages (see Chapter 46).

\section{DISCUSSION}

The sapropelitic series are interbedded with sharp contacts with the "normal" sediments which are, on the Mediterranean Ridge, hemipelagic nanno oozes reflecting a free water circulation.

The beginning of a sapropelitic series is always evidenced by a bed of gray marl ooze which is characterized by a lower calcium carbonate content, suggesting a lower productivity, and by the presence of small amounts of gypsum, indicating a partially restricted environment.

The sapropel beds are very different. As gray marl oozes, they generally have a lower calcium carbonate content than the hemipelagic oozes. This could indicate a lower productivity or, alternatively, when compared with the low quartz content, a dilution in organic matter. In addition, in some sapropel beds the calcium carbonate is very low or even absent. For these beds, the explanation is more likely to be a lower productivity together with a possible dissolution of calcium carbonate on the bottom (Chamley, 1971).

From a mineralogical point of view, sapropels are characterized by the presence of gypsum and the disappearance of some clay minerals. The gypsum indicates neogenesis. The explanation of the disappearance of wellcrystallized illite, when compared to underlying and overlying gray marl oozes and nanno oozes, is more subtle. We may assume that the assemblages of clay minerals inherited from the continents had not consistently changed during the short sapropelitic periods. This suggests that some clays were modified or destroyed during this period. Similar phenomena have been observed on the continents where, in some soils, hydrolysis of clays takes place. For example, in the marsh underclays, mica (i.e., illite) is transformed into chlorite and then into interstratified clays (see Millot, 1964 and MacMillan, 1956, In Chamly, 1971). The final results of these alterations are similar to those observed in our marine sapropel beds. In a similar way,

Figure 5. Turbidite and contourite sapropel sequences of the Hellenic Trough. The Upper Sapropel (0.65 my) sequences are characterized by fair amounts of quartzose sand and silts interbedded (with sharp boundaries) with black marl ooze (127-6, Sections 2 and 3). The Lower Sapropel (1.5 my) is generally characterized by thin contourites. Each sequence starts with a yellow sapropel overlain by a layer of light gray and plastic marl ooze (127-14-5). 

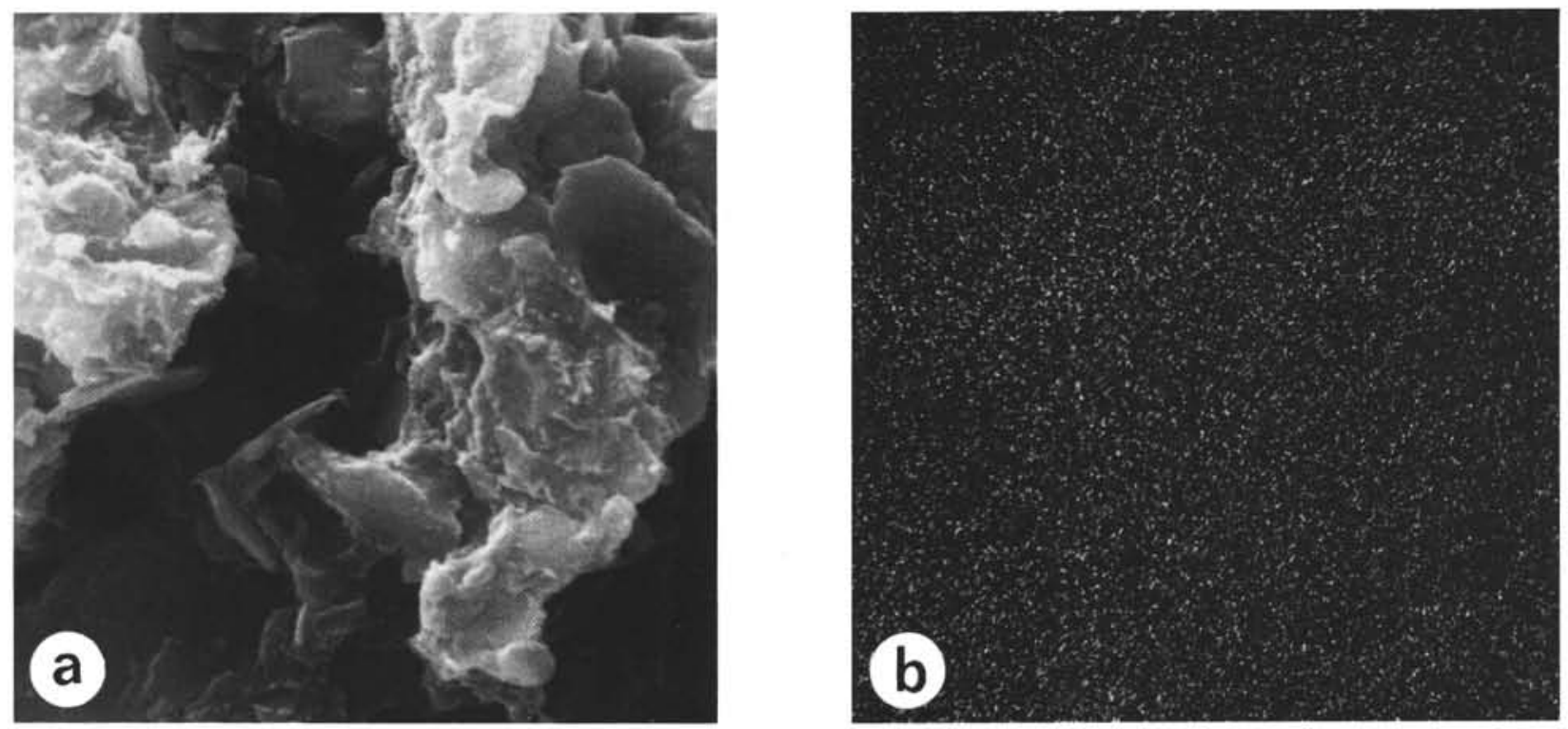

Figure 6. Scanning Electron Microscope picture of a pelagic sapropel (125-3-1, $136 \mathrm{~cm})$. Figure " $a$ " depicts the poorly crystalline aspect with dominant organic matter of the sample. Figure " $b$ " is a Fe scan image. It shows that the iron (as pyrite) is disseminated throughout the sample as tiny crystals.

Chamley (1971) noted in the Holocene sapropels of the eastern Mediterranean Basin the disappearance of smallsized and poorly crystallized illite. The different authors generally agree that tyis type of degradation is caused by the action of organic matter. Laboratory experiences have indeed shown that organic acids are able to degrade clay minerals.

Thus during sapropelitic periods, a very special chemical milieu develops in the thin layer of sapropelitic deposits coating the bottom of the sea. In this environment, alteration of clays, especially illite, takes place in the presence of organic matter. An important neogenesis of gypsum also occurs.

The sapropelitic series display, from a stratigraphic point of view, different rhythms and cycles, in which a general trend is noted. The series always start with a bed of gray marl ooze which indicates a restriction in basin circulation. This gray ooze is topped by a sapropel layer, pointing to a sudden stagnation. Later, as suddenly as they started, the stagnant conditions disappear and are followed by a return to hemirestricted circulation (gray marl oozes) or by a return to normal open-sea conditions (nanno oozes). In addition, series of beds tending toward stagnant conditions without being true sapropels were observed in the Tyrrhenian Sea at Site 132 (see Chapters 19 and 46). This series occurs in synchronism with the eastern basin's sapropels, indicating that the restriction of oceanic circulation effected the whole Mediterranean Sea at the same time, the eastern basin being more severly restricted.

TABLE 2

Organic Matter Analysis of Two Sapropel Beds

\begin{tabular}{lccc}
\hline & $\begin{array}{c}\text { \% Chloroform } \\
\text { Extractable }\end{array}$ & $\begin{array}{c}\text { \% Total Carbon } \\
\left(800^{\circ} \mathrm{C}\right)\end{array}$ & $\begin{array}{c}\text { Degradation } \\
\text { Rate }\end{array}$ \\
\hline $125-3-1,136 \mathrm{~cm}$ & 0.75 & 4.1 & 43 \\
$125-3-4,40 \mathrm{~cm}$ & 0.97 & 5.2 & 45 \\
\hline
\end{tabular}

Olausson (1960, 1961), followed by Ryan (1970), proposed that the stagnant sapropelitic conditions may have been produced by massive flows of fresh water from the Black Sea during the interglacial episodes of ice melting. Superficial sheets of fresh water spread over all the eastern basin would have brought about mass mortality of planktonic life and stagnant conditions on the bottom.

Our observations of Leg 13 sapropelitic series does not entirely support this hypothesis. The partial restriction of the oceanic circulation in the eastern basin (gray marl oozes) followed by complete restriction (sapropels) and the synchronism of these events with the western basin are difficult to explain by the single process of spreading fresh water sheets over the eastern basin. They need a more complex mechanism and suggest a mechanical or dynamic restriction of the free water transport through the different straits connecting the Mediterranean Basins with the world ocean.

The eastern basin of the Mediterranean, in which true sapropels occur, is separated today from the western basin by the Sicily Straits, 450 meters deep, and the Straits of Messina, 120 meters deep. To the southeast, the Red Sea was connected with the Mediterranean Sea at the beginning of the Pliocene. The exact date of its isolation from the Mediterranean system is not known. It occurred sometime during the Pliocene or even the lower Quaternary, and the presence or absence of sapropels in the Red Sea may help to solve this problem. In any case, the eastern basin was closed toward the east and southeast and communication with the world ocean occurred mainly through the Straits of Sicily. These straits consist of a shallow plateau $(150 \mathrm{~m}$ average depth) incised by a narrow and deep channel $(450 \mathrm{~m})$. In turn, the western basin communicates with the Atlantic through the Gibraltar Straits, 550 meters deep.

A glacio-eustatic lowering of sea level during the Quaternary glaciations could have reduced the water transport between the basins. However, faunal evidence 
indicates that the sapropelitic episodes occurred during the warm trends of the fluctuating climate, i.e., during the interglacial intervals. Thus the stagnations of the eastern basin and the restrictions in the circulation of the western basin should not be related to sea level oscillations.

An alternative is a dynamically stagnant basin, similar to the model proposed for the Recent stagnant episodes of the Cariaco Trench by Heezen et al., 1959. Today, the Mediterranean Sea circulates because its water balance is negative. Light Atlantic water, flowing on the surface through the Gibraltar Straits compensates for this deficiency. In the Mediterranean basins, water is evaporated and cooled during winter. It sinks and cascades down, creating a vertical circulation. In turn this dense water escapes the Atlantic over Gibraltar Straits. It is possible to envision a different model, if the situation is reversed during a warm interglacial episode and the water balance becomes positive due to massive flows of fresh water from melting glaciers. In this case, light Mediterranean water would flow on the surface toward the west through the Gibraltar Straits, but dense Atlantic water, once it had filled the bottom of the basins to the brim of the sills, would not circulate any more because no vertical mixing would occur; the warm climate preventing the cooling and sinking of the surface water. This situation would last some thousands of years.

In conclusion, a dynamic model of stagnations can explain the occurrence of sapropels in the eastern Mediterranean. Poor bottom circulation would initiate the deposition of gray marl oozes, and stagnant conditions the deposition of sapropels.

\section{REFERENCES}

Chamley, H., 1971. Recherches sur la sédimentation argileuse en Méditerranée. Thése Sciences, Aix Marseille.

Giraud, A., 1970. Application of pyrolysis and gas chromatography to geochemical characterization of kerogen in sedimentary rocks. AAPG. Bul. 54 (3), 439.

Heezen, B. C., Menzies, R. J., Broecker, W. S. and Ewing, W. M., 1959. Stagnation of the Cariaco Trench. Preprints, First Internation Oceanographic Congress, New York. M. Sears (Ed.) Am. Ass. As. Science.

Kullenberg, B., 1952. On the salinity of the water contained in marine sediments. Medd. Oceanografiska Inst. Goteborg. 21.

Olausson, E., 1960. Description of sediment from the Mediterranean and the Red Sea. Rep. Swedish Deep-Sea Exped., 1947-1948. 8 (3), 287. 1961. Studies of deep sea cores. Sediment cores from the Mediterranean Sea and the Red Sea. Rept. Swedish Deep-Sea Expd., 1947-1948. 8, 337.

1965. Evidence of climactic changes in North Atlantic Deep Sea Cores. Progress in Oceanography, 3, 224. Pergammon Press, London.

Ryan, W. B. F., 1970. PhD Thesis. University of Columbia, New York.

Rossignol, M. and Pastouret, L., 1971. Analyze pollènique de niveaux sapropèlitiques, post-glaciaires dans une carotte en Méditerranée Orientale. Rev. Palacobot. Palynol. (In Press).

Wijmstra, T. A., 1969. Palynology of the first 30 meters of a 120 meter deep section in Northern Greece. Act. Bot. Neerl. 18 (4), 511. 